\title{
CFD predictions of Swirl burner aerodynamics with variable outlet configurations
}

\author{
Hesham Baej ${ }^{1}$ \\ College of Physical Sciences and Engineering, \\ Cardiff University \\ Nick Syred ${ }^{3}$ \\ College of Physical Sciences and Engineering, \\ Cardiff University \\ Phil Bowen ${ }^{5}$ \\ College of Physical Sciences and Engineering, \\ Cardiff University
}

\begin{abstract}
Swirl stabilised combustion is one of the most widely used techniques for flame stabilisation in gas turbine combustors. Lean premixed combustion systems allow the reduction of NOx coupled with fair flame stability. The swirl mechanism produces an aerodynamic region known as central recirculation zone (CRZ) providing a low velocity region where the flame speed matches the flow velocity, thus anchoring the flame whilst serving to recycle heat and active chemical species to the root of the former. Another beneficial feature of the CRZ is the enhancement of the mixing in and around this region. However, the mixing and stabilisation processes inside of this zone have shown to be extremely complex. The level of swirl, burner outlet configuration and combustor expansion are very important variables that define the features of the CRZ.
\end{abstract}

Therefore, in this paper swirling flame dynamics are investigated using computational fluid dynamics (CFD) with commercial software (ANSYS). A new generic swirl burner operated under lean-premixed conditions was modelled. A variety of nozzles were analysed using several gaseous blends at a constant power output. The investigation was based on recognising the size and strength of the central recirculation zones. The dimensions and turbulence of the Central Recirculation Zone were measured and correlated to previous experiments. The results show how the strength and size of the recirculation zone are highly influenced by the blend and infer that it is governed by both the shear layer surrounding the Central Recirculation Zones (CRZ) and the gas composition.

\section{NOMENCLATURE}

$\begin{array}{cl}\mathrm{U} & \text { Axial velocity }[\mathrm{m} / \mathrm{s}] \\ \mathrm{U} & \text { Fluctuating axial velocity }[\mathrm{m} / \mathrm{s}] \\ \mathrm{W} & \text { Tangential velocity }[\mathrm{m} / \mathrm{s}] \\ \rho & \text { Density }[\mathrm{kg} / \mathrm{m} 3] \\ \mathrm{r} & \text { Radius }[\mathrm{m}] \\ \mathrm{n} & \text { Number of products } \\ Y_{i} & \text { Mass fraction of product species } \mathrm{i} \\ Y_{i, e q} & \text { Equilibrium mass fraction of product } \\ & \text { species } \mathrm{i}\end{array}$

\author{
Agustin Valera-Medina ${ }^{2}$ \\ College of Physical Sciences and Engineering, \\ Cardiff University \\ Richard March ${ }^{4}$ \\ College of Physical Sciences and Engineering, \\ Cardiff University
}

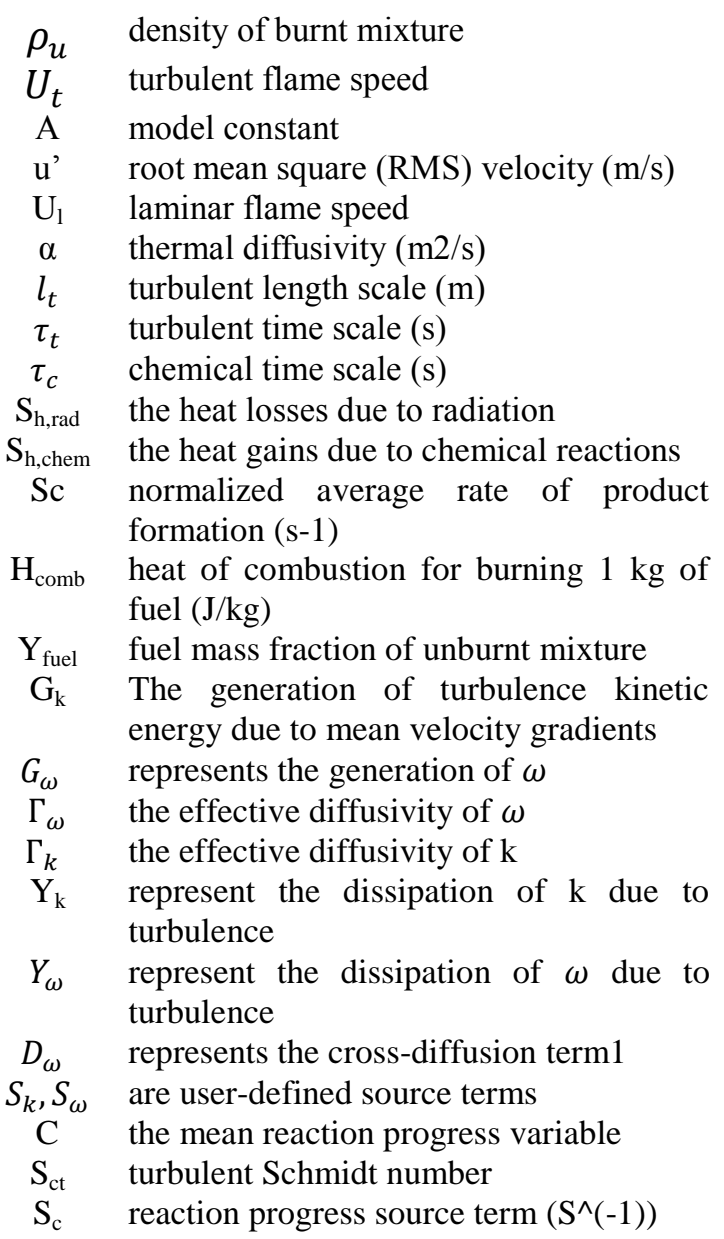

\section{INTRODUCTION}

A proved technology to reduce the impact of NOx is the use of lean premixing with swirl stabilized combustion. Swirling flow technologies have shown to give high flame stability taking advantage of coherent structures such as corner and central recirculation zones which anchor the flame, recirculating hot products and active chemical species whilst also increasing their residence time, allowing the use of low equivalence ratios thus giving lower flame temperatures and NOx emissions [1]. 
However, premixed combustion is not perfect because fuel and air mix just before entering the combustion chamber, thus leading to a significant degree of un-mixedness. These create complex instabilities which would feedback into the mixingreaction combustion process. Combustion instabilities remain a critical issue limiting the development of low emission, lean premixed gas turbine combustion systems. Strong efforts are currently undertaken for the numerical simulation of swirl stabilized flames with the intention of designing improved gas turbine combustors [2-3].

The biggest challenge to fuel-flexibility of most combustors is the large differences between natural gas and the proposed replacement fuels. Moreover, gas turbines must meet the current emissions regulations, which often mean running very near lean blowoff. However, blowoff continues to be a phenomenon that is difficult to predict across reactor types and fuel compositions. To describe the lean blowoff behaviour of swirl combustors under various fuel compositions, correlations have to be determined and simplified models developed to allow the implementation of fuel flexible technologies [4].

The crucial feature of swirl burners is the formation of a central recirculation zone (CRZ) which extends blowoff limits by recycling heat and active chemical species to the root of the flame in the burner exit [5-6]. Thus, the CRZ is one of the mechanisms for flame stabilization that through an aerodynamically decelerated region creates a point where the local flame speed and flow velocity match [7]. A vast amount of literature exists on measuring, correlating and predicting blowoff limits for bluff body and swirl stabilized combustors. There are three basic characterizations of the physical phenomena responsible for blowoff. Longwell et al. [8] suggested that blowoff occurs when it is not possible to balance the rate of entrainment of reactants into the recirculation zone, viewed as a well stirred reactor, and the rate of burning of these gases. A different view is that the contact time between the combustible mixture and hot gases in the shear layer must exceed a chemical ignition time. This leads to scaling the characteristic dimension by the recirculation zone length, leading to a similar Da criterion [9]. Current theories are based on a flamelet based description upon local extinction by excessive flame stretch [10]. Flame stretching starts blowoff with the initiation of holes in the flame, that are healed by the same flame creating stretching in areas that otherwise would have been unaffected. Flame will extinguish when flame stretch rate exceeds a critical value. However, it is also recognized that this mechanism is not the one causing the final blowoff, as it is clear from data that the flame can withstand some extinction [11]. Therefore, it is considered that the "critical extinction level" must be somehow influenced by other mechanisms [8-9]. Regarding the central recirculation zone, the use of different configurations has demonstrated that the shape and strength of the CRZ can change drastically depending on these alterations [12-13]. Valera-Medina et al. [13] have observed how the change of the combustor nozzle can produce different central recirculation zones under the same injection conditions.

Lieuwen et al [14] investigated the impact of fuel composition on the operability of lean premixed gas turbine combustors focusing on $\mathrm{H}_{2} / \mathrm{CH}_{4}$ flames. They showed that small additions of $\mathrm{H}_{2}$ substantially enhance the mixture's resistance to extinction or blowoff. For example, fundamental studies show that the extinction strain rate of methane flames is doubled with the addition of $10 \% \mathrm{H}_{2}$. Similarly, $\mathrm{CO} / \mathrm{CH}_{4}$ flames showed a variance in their extinction strain rate. Experiments were also conducted using $\mathrm{N}_{2}, \mathrm{H}_{2} \mathrm{O}$ and $\mathrm{CO}_{2}$. They concluded that the flame speeds of mixtures with $\mathrm{CO}_{2}$ dilution are lower than those of mixtures diluted with chemically inert species with the same specific heat as $\mathrm{CO}_{2}$. The $\mathrm{CO}_{2}$ dilution can lead to lower laminar flame speeds and lower flame temperatures due to radiative losses from the flame, which can also impact emissions [11]. Shelil et al. [15] defined the stability limits of flames regarding flashback and correlated it to the mean mixture velocity at the burner exit. They determined the flashback limits, numerically, for $\mathrm{H} 2 / \mathrm{CH} 4$ blends ranging from $0 \%$ (pure methane) up to $100 \%$ (pure hydrogen) based on the volumetric composition at atmospheric pressure and $300 \mathrm{~K}$ for various equivalence ratios. Their results showed that the use of up to $50 \%$ blends of methane and hydrogen causes fewer problems with flame stability and flashback compared with the use of pure hydrogen, as observed by Liewen et al [14]. However, there is still a considerable need for experimental and numerical correlations of different stability phenomena and fuel blends in gas turbines.

On the other hand, significant progress has been made in the development of computational fluid dynamics (CFD) to simulate the performance of practical combustion systems over the last two decades. These models are now increasingly being used for the evaluation of performance and to assist in the design and development of such combustors. Reliable predictions of the combustion and pollutant formation processes occurring in the near burner region critically depend on the accuracy of the turbulent flow field calculation. The emission reduction, especially of $\mathrm{NOx}$, has been the major driver for gas turbine development in these decades. In the fields of combustion science and engineering, CFD calculations is now truly competitive with experiment and theory as a research tool to produce detailed and multi-scale information about combustion processes, playing a crucial role in the design of environment friendly processes. In particular, gas turbine combustion modelling, involving the interaction of many complex physical processes such as turbulent mixing, chemical reactions etc., comprises a range of computational and modelling challenges [16].

The shear-stress transport (SST) k- $\omega$ turbulence model is generally employed for swirling flows. The limitations of this model for predictions of both non-combusting (isothermal) and combusting swirling flows, in particular, the size and strength 
of the swirl-induced Central recirculation zone (CRZ), are well known $[15,17]$.

Therefore, in this paper the CFD code Fluent is used to simulate a swirl premixed combustion system. A three dimensional model is used to study the flame stability and determine the process and CRZ size close to the blowoff phenomenon. The stability limits are defined and correlated to both total mass flow rate and equivalence ratios. Methane and carbon dioxide fuel blends were studied and compared with combustion of pure methane.

\section{NUMERICAL METHODOLOGY}

CFD modelling was used to simulate the combustion of a premixed swirl burner that uses different types of fuels. A $100 \mathrm{~kW}$ swirl burner constructed from stainless steel was used to examine the flame stability limits at atmospheric conditions (1 bar, $293 \mathrm{~K})$ at Cardiff University's Gas Turbine Research Centre (GTRC). Different nozzles were used with various angles: $30^{\circ}, 45^{\circ}, 60^{\circ}, 90^{\circ}$, with two swirl numbers of 1.05 and 1.50. A single tangential inlet (a) feeds the premixed air and fuel to an outer plenum chamber (b) which uniformly distributes the gas to the slot type radial tangential inlets (c). Swirling unburned fuel then passes into the burner body (d), then into the burner exhaust (e) where the gases pass around the flame stabilizing central recirculation zone. The central diffusion fuel injector (f) (which was not used for fuel during the course of this study) extends centrally through the combustor body to the exhaust, Figure 1 .

CFD modelling is initially performed to simulate the combustion of methane-air without/with carbon dioxide. Laminar flame speeds were calculated for pure methane and $\mathrm{CH}_{4} / \mathrm{CO}_{2}$ blends at atmospheric pressures, $300 \mathrm{~K}$ and various equivalence ratios. This was done using CHEMKIN-PRO with PREMIX code. The numerical values for the laminar flame speeds were then fed into the CFD model. Isothermal conditions with no combustion were used to calibrate the system and indicate the flow pattern, although it is well known that there are also 3D time, dependant coherent structures, thus the results are of an indicative nature. During the simulation, various types of solvers were investigated and conclusions drawn as to which were the most effective. Based on the experimental results obtained at 5.85 and $5.48 \mathrm{~g} / \mathrm{s}$ total mass flow rates, the best turbulent option for the present work was the $\kappa-\omega$ SST model $[11,18-20]$.

Swirl combustor and burners are usually characterized by the degree of swirl, via a swirl number (S). For this particular project, the swirl element of 1.05 has four tangential inlets symmetrically distributed, whilst the swirl element of 1.50 has nine tangential inlets symmetrically distributed. The swirl burner gives good flame stabilization, but produces a CRZ that extends back over the central fuel injector, allowing the flame to propagate into this region. This effect can be reduced by fitting a divergent of the exhaust nozzle of the burner, as shown in Figure 2, producing a different CRZ.

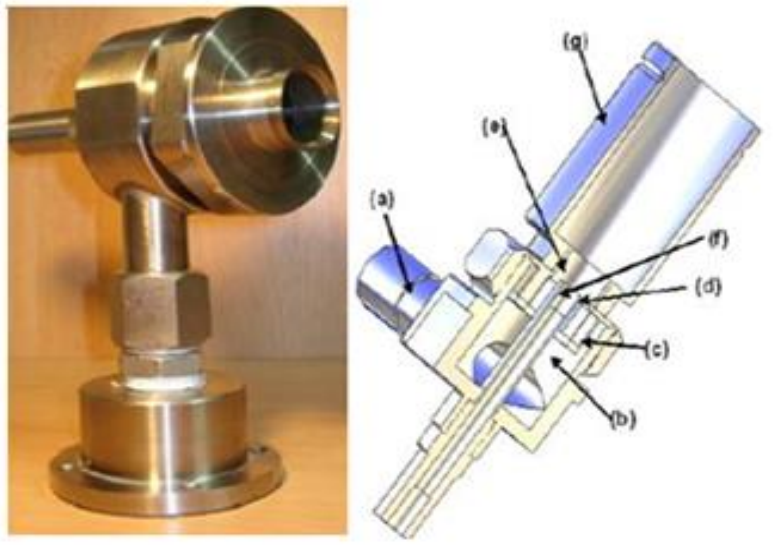

Figure 1. Swirl burner and schematic diagram, respectively

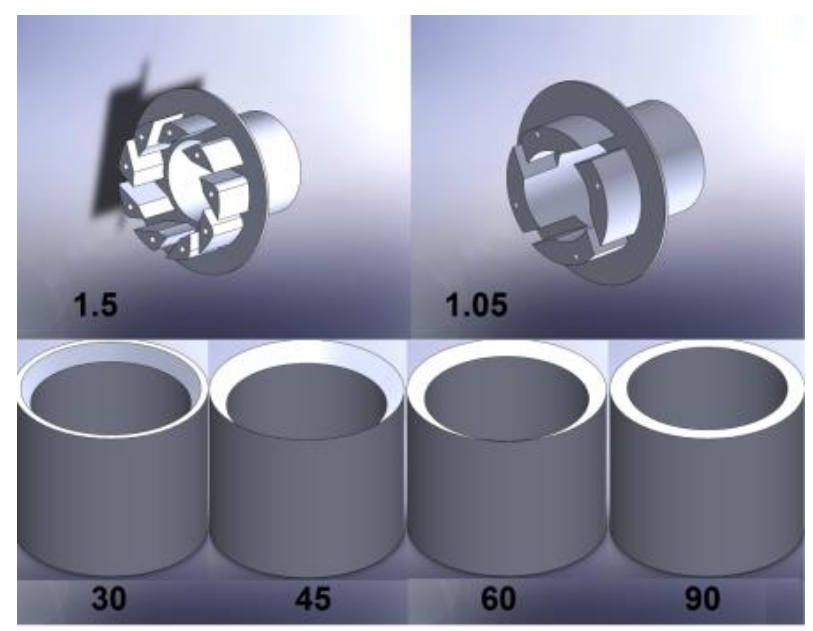

Figure 2. Geometrical swirl number 1.50, 1.05 and various divergent angles nozzles, respectively.

\section{Premixed Combustion Modelling}

In premixed combustion fuel and oxidizer are mixed prior to ignitions [18]. Combustion occurs as a flame front propagates into the unburnt reactants. However, premixed combustion is much more difficult than non-premixed combustion. The reason for this is that premixed combustion usually occurs as thin, propagating flames that stretch and contort by turbulence. For subsonic flows, the overall rate of propagation of the flame is determined by both the laminar flame speed and the turbulent eddies. The laminar flame speed is determined by the rate that species and heat diffuse upstream into the reactants and burn. The flame front propagation is modelled by solving a transport equation for the density-weighted mean reaction progress variable, denoted by c [21]:

$$
\frac{\partial}{\partial t}(\rho c)+\nabla \cdot(\rho \vec{v} c)=\nabla \cdot\left(\frac{\mu_{t}}{S_{c t}} \nabla c\right)+\rho S_{c}
$$


The progress variable is defined as a normalized sum of the product species,

$$
c=\sum_{i=1}^{n} Y_{i} / \sum_{i=1}^{n} Y_{i, e q}
$$

Based on this definitions $c=0$ where the mixture is unburnt and $\mathrm{c}=1$ where the mixture is burnt. And the value of $\mathrm{c}$ is defined as a boundary condition at all flow inlets. It is usually specified as either 0 (unburnt) or 1 (burnt). The mean reaction rate in equation (4) is modelled as,

$$
\rho S_{c}=\rho_{u} U_{t}|\nabla c|
$$

The turbulent flame speed computed from this equation

$$
U_{t}=A\left(u^{\prime}\right)^{3 / 4} U_{i}^{1 / 2} \alpha^{-1 / 4} l_{t}^{1 / 4}=A u^{\prime}\left(\frac{\tau_{t}}{\tau_{c}}\right)^{1 / 4}
$$

The turbulent length scale $l_{t}$ is computed from

$$
l_{t}=C_{D} \frac{\left(u^{\prime}\right)^{3}}{\epsilon}
$$

The default values of 0.52 for $A$ and 0.37 for $C_{D}$ are recommended by Zimont et al [19].

The energy transport equation is solved in order to account for any heat losses or gains within the system. These losses may include heat sources due to chemical reaction or radiation heat losses. The energy equation in terms of sensible enthalpy, $\mathrm{h}$, for the premixed fuel is as follows,

$$
\begin{aligned}
& \frac{\partial}{\partial t}(\rho h)+\nabla \cdot(\rho \vec{v} h)=\nabla \cdot\left(\frac{k+k_{t}}{c_{p}} \nabla h\right)+S_{h, \text { chem }}+S_{h, \text { rad }} \\
& \mathrm{S}_{\mathrm{h}, \text { chem }}=\rho \mathrm{S}_{\mathrm{c}} \mathrm{H}_{\text {comb }} \mathrm{Y}_{\text {fuel }}
\end{aligned}
$$

\section{Turbulence modelling}

The turbulence model used was the shear-stress transport (SST) $\mathrm{k}-\omega$ model, so named because the definition of the turbulent viscosity is modified to account for transport of the principal turbulent shear stress. It has features that give the SST k- $\omega$ model an advantage in terms of performance over both the standard K- $\omega$ model and standard k- $\epsilon$ model. Other modifications include the addition of a cross-diffusion term in the $\omega$ equation and a blending function to ensure that the model equations behave appropriately in both the near-wall and far field zones. The turbulence kinetic energy, $\mathrm{k}$, and the specific dissipation rate, $\omega$, are obtained from the following transport equations:

$$
\frac{\partial}{\partial t}(\rho k)+\frac{\partial}{\partial_{x_{i}}}\left(\rho k u_{i}\right)=\frac{\partial}{\partial x_{i}}\left(\Gamma_{k} \frac{\partial k}{\partial x_{j}}\right)+\tilde{G}_{k}-Y_{k}+S_{k}
$$

$$
\frac{\partial}{\partial t}(\rho \omega)+\frac{\partial}{\partial_{x_{i}}}\left(\rho \omega u_{i}\right)=\frac{\partial}{\partial x_{i}}\left(\Gamma_{\omega} \frac{\partial \omega}{\partial x_{j}}\right)+\widetilde{G}_{\omega}-Y_{\omega}+D_{\omega}+S_{\omega}
$$

Calculations for all previous terms have been fully described in [22].

\section{Mesh distribution and Boundary Conditions}

Pure methane and methane blends with carbon dioxide were used to compare experiments based on previous works [23-24]. The gas composition and the operating conditions of the burner are given in Table 1,

Table 1. Inlet boundary conditions

\begin{tabular}{|l|l|l|l|l|l|l|}
\hline $\begin{array}{l}\text { Te } \\
\text { st }\end{array}$ & \multicolumn{1}{l}{ Inlet } & \multicolumn{1}{l}{$\begin{array}{l}\text { Inlet } \\
\text { P }\end{array}$} & $\begin{array}{l}\text { CH4 } \\
{[\mathrm{g} / \mathrm{s}]}\end{array}$ & $\begin{array}{l}\text { AIR } \\
{[\mathrm{g} / \mathrm{s}]}\end{array}$ & $\begin{array}{l}\text { CO2 } \\
{[\mathrm{g} / \mathrm{s}]}\end{array}$ & $\begin{array}{l}\text { Total } \\
{[\mathrm{g} / \mathrm{s}]}\end{array}$ \\
\hline T1 & $300 \mathrm{~K}$ & 1 bar & 0.27 & 5.5 & None & 5.85 \\
\hline T2 & $300 \mathrm{~K}$ & 1 bar & 0.27 & 4.94 & 0.27 & 5.48 \\
\hline
\end{tabular}

FLUENT 14.5 was used to achieve the modelling and simulation [25]. The pre-processor used to construct the model grid was ICEM 14.5.7. The computational mesh consists of 149,634 elements, with a structured grid created with a higher density of nodes in areas where the fluid flow was expected to considerably change and where a finer grid resolution was assumed to be beneficial for achieving an accurate resolution. This was essentially done close to the burner exit and around the fuel nozzles, Figure 3.

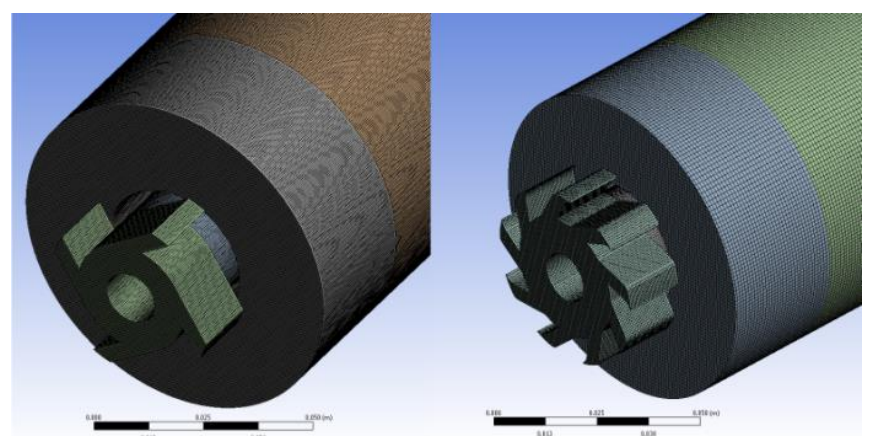

Figure 3. Mesh distribution swirl numbers 1.05 and 1.50, respectively

\section{RESULTS AND DISCUSSIONS}

Isothermal conditions were simulated first to ensure mesh independency and good accuracy in the results. Afterwards, combustion analyses were carried out. The comparison of the CFD simulation presented in Figure 4(a) and (b) reveals the effects of combustion on the flow pattern. The predicted and measured boundaries of the CRZ for isothermal flows show a longer CRZ extending up to the combustor exit, as expected. However, the usage of combustion showed the reduction of both the size and the strength of the CRZ, Table 2.

The reduction of the size and strength of the CRZ in the combusting flow is due to the decrease of the level of swirl in 
the combustor [3]. The measurements show that the axial velocities in the forward flow region increase significantly due to combustion-induced flow acceleration while the tangential velocities are slightly altered. Consequently, the ratio of the tangential to axial momentum fluxes decreases substantially.

Table 2. Comparison of isothermal and combustion patters of the CRZ using different nozzle angles.

\begin{tabular}{|c|c|c|c|c|c|}
\hline & $30^{\circ}$ & $45^{\circ}$ & $60^{\circ}$ & $90^{0}$ & Conditions \\
\hline Width & $1.23 \mathrm{D}$ & $1.34 \mathrm{D}$ & $1.66 \mathrm{D}$ & $1.19 \mathrm{D}$ & ISOTH \\
\hline Higher & $2.65 \mathrm{D}$ & $2.97 \mathrm{D}$ & $3.41 \mathrm{D}$ & $2.93 \mathrm{D}$ & ISOTH \\
\hline Width & $1.19 \mathrm{D}$ & $1.34 \mathrm{D}$ & $1.58 \mathrm{D}$ & $1.15 \mathrm{D}$ & COMBUS \\
\hline Higher & $2.53 \mathrm{D}$ & $2.85 \mathrm{D}$ & $3.29 \mathrm{D}$ & $2.89 \mathrm{D}$ & COMBUS \\
\hline
\end{tabular}

The usage of $\mathrm{CO} 2$ also alters the size and inner turbulence of the structure; in Table 3 and Figures 6-7 it is clear that the turbulence intensity inside the CRZ with methane blends is higher than with pure methane. The use of $\mathrm{CO} 2$ increases in almost $7-10 \%$ the turbulence of the structure, whilst augmenting its width and length in $\sim 10 \%$ for all cases, Figure 5 . The length of the recirculation zone increases due to the reduced reaction time of the blend and the higher turbulence inside of the structure.

The flow rate increases with the intensity of the shear layer. This will converge into a new structure called High Momentum Flow Region (HMFR), highly correlated to the CRZ [24]. This will increase the strength of the CRZ but reduce its dimensions, as observed in table 4 . The addition of $\mathrm{CO} 2$ affects the velocity of the flow, thus showing slower profiles than with pure methane. At the same time, it seems that the dimensions of the CRZ with $\mathrm{CO} 2$ have increased to a width of $1.30 \mathrm{D}$ and height of 3.53D, compared to a width of $1.19 \mathrm{D}$ and a height of $2.53 \mathrm{D}$ with pure methane under similar conditions, Figure 5. Figures 6-7 show the progression of the CRZ and its boundaries, defined as a region of greater turbulence compared to the pure methane case. It is clear that the $\mathrm{CRZ}$ using $\mathrm{CO} 2$ has increased in size.

Table 3 Comparison of turbulent intensity of all cases pure methane and blend with $\mathrm{CO}_{2}$

\begin{tabular}{l|l|l|l|l|l|}
$\begin{array}{l}\text { Gas } \\
\text { mixture }\end{array}$ & $\mathbf{3 0}$ & $4^{\circ}$ & $6^{\circ}$ & $9^{\circ}$ & S \\
\hline $\mathrm{CH} 4$ & $66.6 \%$ & $67.4 \%$ & $65.3 \%$ & $63.5 \%$ & 1.05 \\
\hline $\mathrm{CH} 4+\mathrm{CO} 2$ & $73.6 \%$ & $76.2 \%$ & $74.5 \%$ & $69.4 \%$ & 1.05 \\
\hline $\mathrm{CH} 4$ & $107 \%$ & $109 \%$ & $103.4 \%$ & $95.4 \%$ & 1.5 \\
\hline $\mathrm{CH} 4+\mathrm{CO} 2$ & $116 \%$ & $117 \%$ & $106.8 \%$ & $100.2 \%$ & 1.5 \\
\hline
\end{tabular}

Figure 8 illustrates the axial velocity using different nozzle angles at a constant mass flow rate. The smallest CRZ width size was observed using the $90^{\circ}$ geometry, as expected. Also the $30^{\circ}$ nozzle produces higher outlet velocities than the $60^{\circ}$ and $45^{\circ}$ divergent angles due to the sharp sudden expansion. The $45^{\circ}$ nozzle generates axial velocities $50 \%$ slower than the straight $90^{\circ}$ geometry, thus allowing a better recuperation of the CRZ. This causes an increase in size of CRZ, Figure 5.

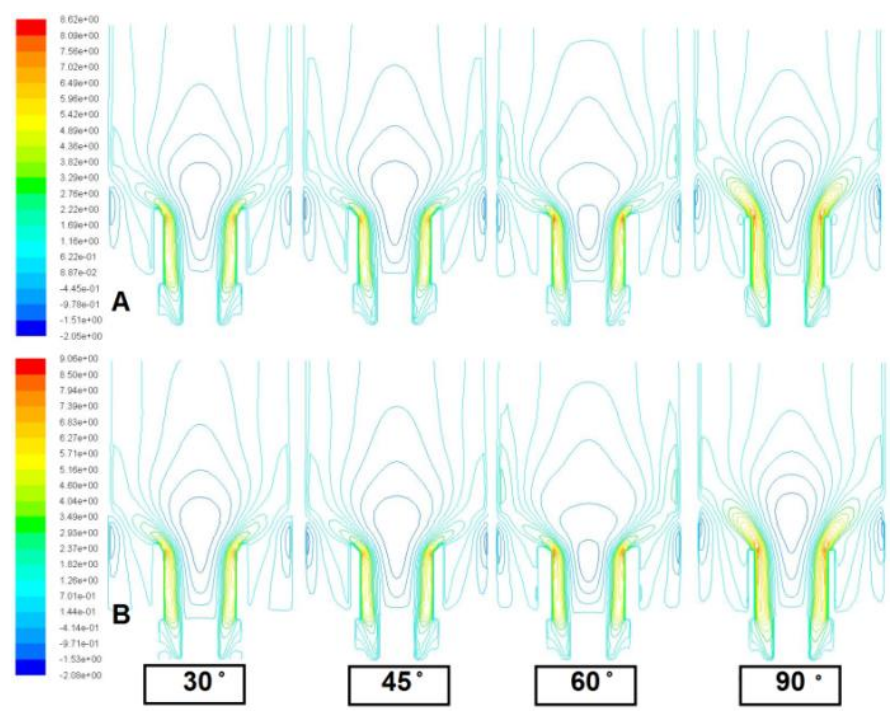

Figure 4. Comparison of isothermal and combustion different nozzles $\mathrm{S}=1.05$ case (a) isothermal and (b) combustion

Table 4. Comparison of CRZ size using all nozzles with swirl numbers of 1.05 and 1.50 .

\begin{tabular}{|c|c|c|c|c|c|c|}
\hline $\mathbf{N}$ & $30^{\circ}$ & $45^{\circ}$ & $60^{\circ}$ & $90^{\circ}$ & $\begin{array}{l}\text { Gas } \\
\text { mixture }\end{array}$ & $\mathbf{S}$ \\
\hline W & $1.19 \mathrm{D}$ & $1.34 \mathrm{D}$ & $1.58 \mathrm{D}$ & $1.15 \mathrm{D}$ & $\mathrm{CH} 4$ & 1.05 \\
\hline$\overline{\mathrm{H}}$ & $2.53 \mathrm{D}$ & $2.85 \mathrm{D}$ & $3.29 \mathrm{D}$ & $2.89 \mathrm{D}$ & $\mathrm{CH} 4$ & 1.05 \\
\hline $\mathrm{W}$ & $1.07 \mathrm{D}$ & $1.27 \mathrm{D}$ & $1.03 \mathrm{D}$ & $0.95 \mathrm{D}$ & $\mathrm{CH} 4$ & 1.50 \\
\hline$\overline{\mathrm{H}}$ & $2.25 \mathrm{D}$ & $3.01 \mathrm{D}$ & $2.85 \mathrm{D}$ & $2.77 \mathrm{D}$ & $\mathrm{CH} 4$ & 1.50 \\
\hline $\mathrm{W}$ & $1.30 \mathrm{D}$ & $1.34 \mathrm{D}$ & $1.60 \mathrm{D}$ & $1.23 \mathrm{D}$ & $\mathrm{CH} 4+\mathrm{CO} 2$ & 1.05 \\
\hline $\mathrm{H}$ & $3.53 \mathrm{D}$ & $2.89 \mathrm{D}$ & $3.51 \mathrm{D}$ & $2.79 \mathrm{D}$ & $\mathrm{CH} 4+\mathrm{CO} 2$ & 1.05 \\
\hline $\mathrm{W}$ & $1.07 \mathrm{D}$ & $1.27 \mathrm{D}$ & $1.03 \mathrm{D}$ & $0.95 \mathrm{D}$ & $\mathrm{CH} 4+\mathrm{CO} 2$ & 1.50 \\
\hline $\mathrm{H}$ & $2.53 \mathrm{D}$ & $3.01 \mathrm{D}$ & $2.89 \mathrm{D}$ & $2.77 \mathrm{D}$ & $\mathrm{CH} 4+\mathrm{CO} 2$ & 1.50 \\
\hline
\end{tabular}

The high momentum shearing flow region illustrated in Figure 9 with both swirl numbers of 1.05 and 1.50 shows the divergence of the flow at the outlet of the nozzle. It is clear that the increase in swirl number will produce higher stretch in the radial and tangential direction with a faster decay of velocity in azimuthal direction and wider CRZs.

Another measured structure was the external recirculation zone (ERZ), Table 5 and Figure 9. As the divergence of HMFR increases, the size of ERZ increased. The High Momentum Flow Region seems to get attached and dragged by the ERZ. 


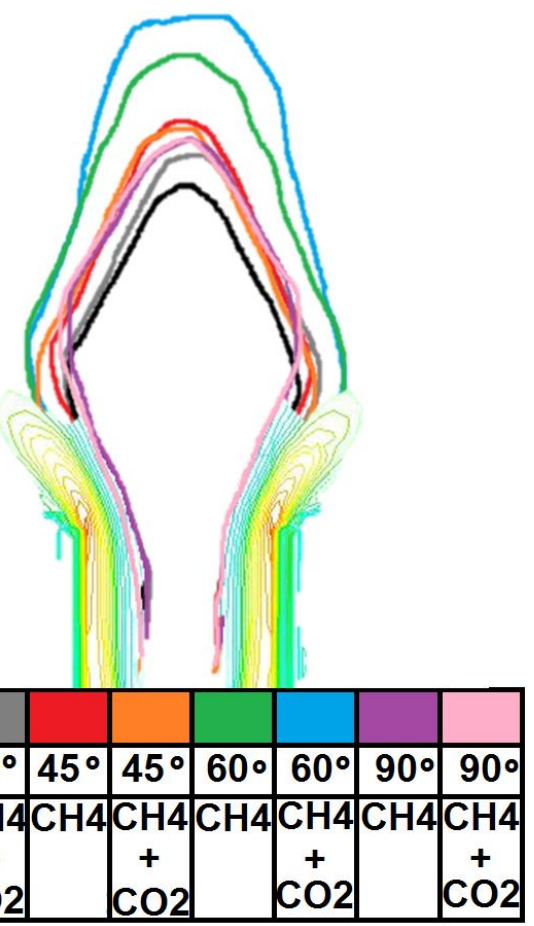

Figure 5. Comparison of CRZ size of all nozzles combustion of methane and methane blend with $\mathrm{CO}_{2}$.

Table 5. Comparison of corner recirculation zones with both swirl number.

\begin{tabular}{|l|l|l|l|l|l|}
\hline & $\mathbf{3 0}^{\mathbf{0}}$ & $\mathbf{4 5}^{\mathbf{0}}$ & $\mathbf{6 0}^{\mathbf{0}}$ & $\mathbf{9 0}^{\mathbf{0}}$ & $\mathbf{S}$ \\
\hline WIDTH & $0.22 \mathrm{D}$ & $0.15 \mathrm{D}$ & $0.13 \mathrm{D}$ & $0.22 \mathrm{D}$ & 1.05 \\
\hline HIGHER & $0.79 \mathrm{D}$ & $0.94 \mathrm{D}$ & $0.71 \mathrm{D}$ & $0.75 \mathrm{D}$ & 1.05 \\
\hline WIDTH & $0.18 \mathrm{D}$ & $0.22 \mathrm{D}$ & $0.28 \mathrm{D}$ & $0.3 \mathrm{D}$ & 1.50 \\
\hline HIGHER & $0.53 \mathrm{D}$ & $0.56 \mathrm{D}$ & $0.79 \mathrm{D}$ & $0.98 \mathrm{D}$ & 1.50 \\
\hline
\end{tabular}

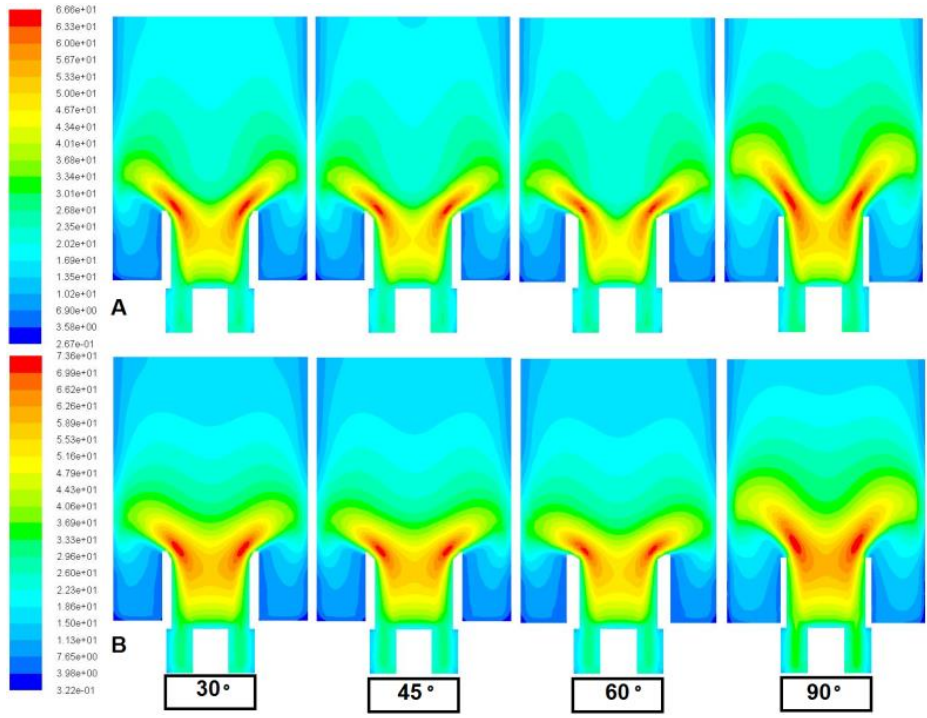

Figure 6. Comparison of turbulence intensity of (a) methane and (b) methane blend with $\mathrm{CO}_{2}$
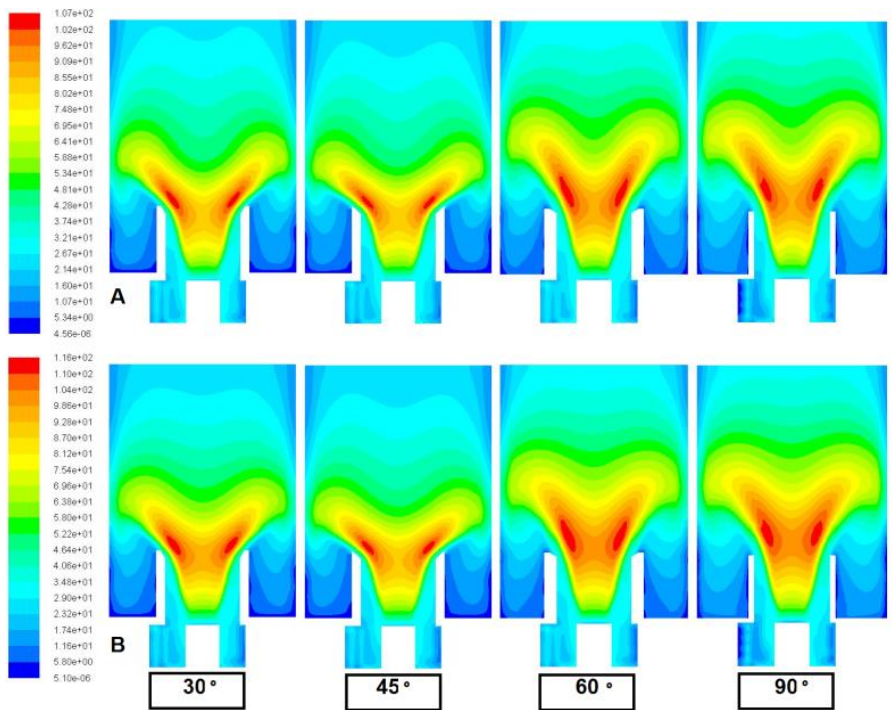

Figure 7. Comparison of turbulence intensity of (a) methane and



Figure 8. Comparison of the axial velocity of different angles.
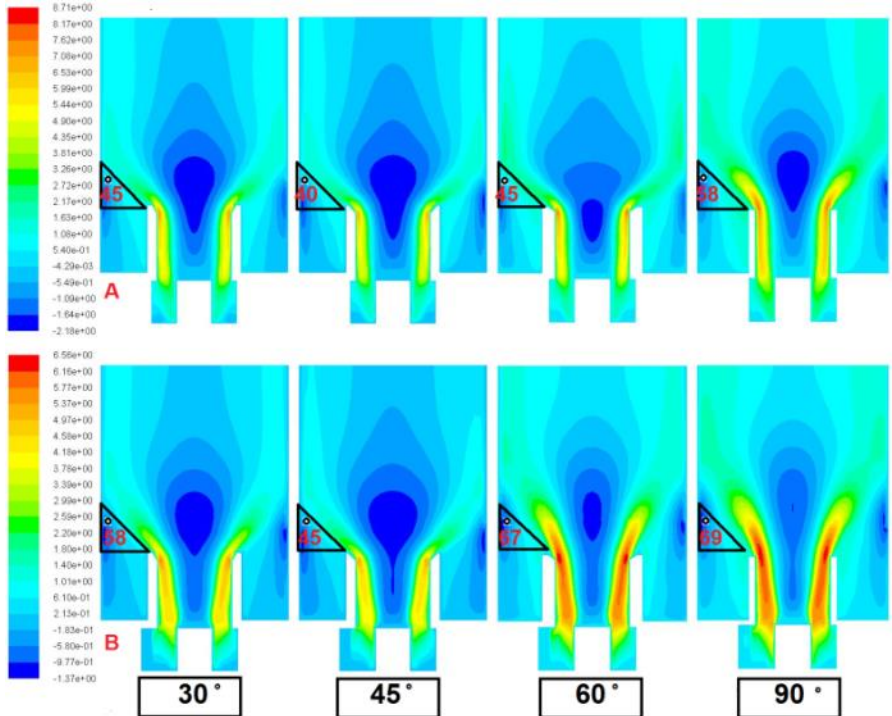

Figure 9. Combustion of methane (a) $\mathrm{S}=1.05$ (b) $\mathrm{S}=1.50$. 


\section{Conclusions}

The CFD predictions of swirl burner aerodynamics show how variable outlet configurations and inert gas compositions change the $\mathrm{CRZ}$ patterns. The addition of $\mathrm{CO} 2$ in the blend with methane can be of great importance to the change of the CRZ. It is clear that the CRZ is increased with the usage of $\mathrm{CO} 2$ whilst changing outlet nozzles angles. Changing the angle of the nozzle will control the direction of shear layer. This in return could be beneficial for new blends and the increase of the residence time of the products/reactants of these and other fuel/diluent compositions. The addition of the $\mathrm{CO} 2$ produces longer recirculation zones that collapse suddenly and far away from the nozzle. The high turbulence of the $\mathrm{CRZ}$ using $\mathrm{CO} 2$ can also be an important parameter in the addition of other species that can improve the combustion process whilst recirculating $\mathrm{CO} 2$ for other applications, ie. carbon capture and storage.

\section{Acknowledgments}

The authors gratefully acknowledge the support of the Welsh Government Low Carbon Research Initiative Programme, the EPSRC (grant no EP/G060053) and the European Union via various grants. Mr. Hesham Baej gratefully acknowledges the support of the Libyan Embassy and the Libyan Cultural and Education Bureau in London during his research.

\section{REFERENCES}

[1]Sadanandan R., Stohr M., Meier W: "Simultaneous OHPLIF and PIV measurements in a gas Turbine model Combustor",Applied Physics B, vol. 90, 609-618 (2008).

[2]Huang, Y., and Yang, V: "Dynamics and stability of leanpremixed swirl stabilized combustion," Progress in Energy and Combustion Science, 35(4), 293-364 (2009).

[3]Syred N,: A review of oscillation mechanisms and the role of the PVC in swirl combustion systems, Prog Energy Combust Sci 32 (2), 93-161(2006).

[4] Megan Karalus: An Investigation of Lean Blowout of Gaseous Fuel Alternatives to Natural Gas, PhD Thesis, University of Washington,(2013).

[5] Lieuwen T, Yang V: Combustion Instabilities in Gas Turbine Engines, Prog. In Astronautics Aeronautics, AIAA, U.S.A., vol. 210, 213-276 (2005).

[6] Tuttle SG, Chaudhuri S, Kotska S, Koop-Vaughan KM, Jensen TR, Cetegen BM, Renfro MW: Time-resolved blowoff transition measurements for two-dimensional bluff bodystabilized flames in vitiated flow. Combust Flame 159, 291305(2012).

[7] Lieuwen T: Unsteady Combustor Physics, Cambridge Press, U.S.A., pp. 430(2012).

[8] Longwell JP, Frost EE, Weiss MA: Flame stability in bluff body recirculation zones. Indust Eng Chem 8, 1629-1633 (1953).
[9] Shanbhogue SJ, Husain S, Lieuwen T: Lean blowoff of bluff body stabilized flames: Scaling and dynamics, Prog Energy Combust Sci, 35, 98-120 (2009).

[10]Driscoll J: Turbulent premixed combustion: flamelet structure and its effect on turbulent burning velocities, Progress in Energy and Combustion Science 34 (1), 91-134(2008).

[11] Poinsot T, Veynante D: Theoretical and Numerical Combustion, R.T. Edwards, U.S.A., pp. 522(2005).

[12]Valera-Medina A, Syred N, Bowen P :Central Recirculation Zone Analysis using a Confined Swirl Burner for Terrestrial Energy, J AIAA Propulsion and Power 29 (1), 195204 (2013).

[13]Valera-Medina A, Syred N, Griffiths A Visualization of Coherent Structures in a Swirl Burner under Isothermal Conditions. Combustion and Flame 159,1723-1734 (2009).

[14] Shelil, N., Bagdanavicius, A., Griffiths, A. J., Roberts, P., and Syred, N: "Flashback Analysis for Hydrogen/Methane Mixtures for Premixed Swirl Combustion," The 16th IFRF Members' Conference in Boston, IFRF, USA (2009).

[15] Lieuwen, T, McDonell, V, Petersen, E, Santavicca, D: Fuel flexibility influences on premixed combustor blowout, flashback, autoignition, and stability. J. Eng. Gas Turbines Power 130, 011506 (2008).

[16] Raman V Pitsch H: Large-eddy simulation of a bluff-bodystabilized non-premixed flame using a recursive filterrefinement procedure. Combustion and Flame 142 (4) 329347(2005).

[17]German A E , Mahmud T :Modelling of non-premixed swirl burner flows using a Reynolds-stress turbulence closure. Fuel 84 (5) 583-594(2005).

[18] Versteeg HK and Malalasekera W, An Introduction to Computational Fluid Dynamics - The Finite Volume Method, Longman Group Ltd (1995).

[19] Date A W: Introduction to Computational Fluid Dynamics, Cambridge University Press (2005).

[20] Syred, N.J M.Beer: Combustion in swirling flows: A review combustion and flame 23,143-201(1974)

[21] Zimont, V., Polifke, W., Bettelini, M., and Weisenstein, W., July, "An Efficient Computational Model for Premixed Turbulent Combustion at High Reynolds Numbers Based on a Turbulent Flame Speed Closure," J. of Gas Turbines Power, 120, 526- 532(1998).

[22] ANSYS FLUENT 12.0 Theory Guide 2009 [Online]. Available:at $\quad$ www.scribd.com/doc/191713736/Ansys-Fluent12-0-Theory-Guidem

[23] Baej H., Valera-Medina A., Bowen P., Syred N., O’Doherty T., Marsh R ., Impacts on Blowoff by a variety of CRZs using various gases for Gas Turbines

[24] Vigueras-Zuniga MO, Valera-Medina A, Syred N, Bowen P: High Momentum Flow Region and Central Recirculation Zone Interaction in Swirling Flows, SOMIM. Approved [25] Zimont V, Gas Premixed Combustion at High Turbulence. Turbulent Flame Closure Model Combustion Model. Exp Thermal Fluid Sci 21:179- 186 (2000). 